\title{
ABNORMAL GROUPING OF LARGE EDDIES IN A SUBMERGED JET
}

\author{
BY S.K.A. NAIB, B.Sc. (Eng.) Ph.D., D.I.C., A.C.G.I. *
}

It is well known that when a turbulent jet flows through an enveloping fluid, the surface of discontinuity breaks up into vortices which are carried alternatively along the surface. The development of these vortices in the course of flow of a jet issuing from a submerged sluice-way and diffusing into the water downstream has been previously described $[1,2]$. The vortices grow with distance and eventually extend to the water surface through

* Principal Lecturer in Fluid Mechanics, West Ham College of Technology, London, E. Ts. the entire height of the circulation zone. The mixing produced by these vortices simultaneously causes the jet to expand until its upper limit momentarily reaches the free surface, where it divides and a stagnation point develops.

In the course of experiments to study the diffusion of the jet, it was observed that a particular kind of unsteadiness developed involving abnormal grouping of large eddies in the flow, a phenomenon which was clearly observed in semi-submerged patterns, as shown in Figure 1 a. Here, two large eddies $\mathrm{A}$ and $\mathrm{B}$ are indicated near the middle of the

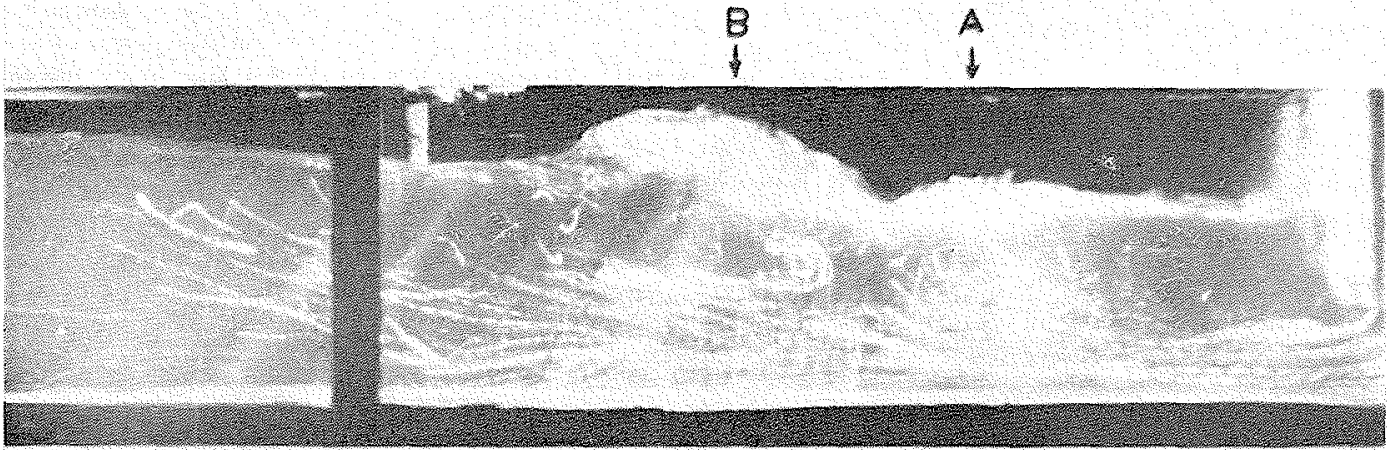

(a)

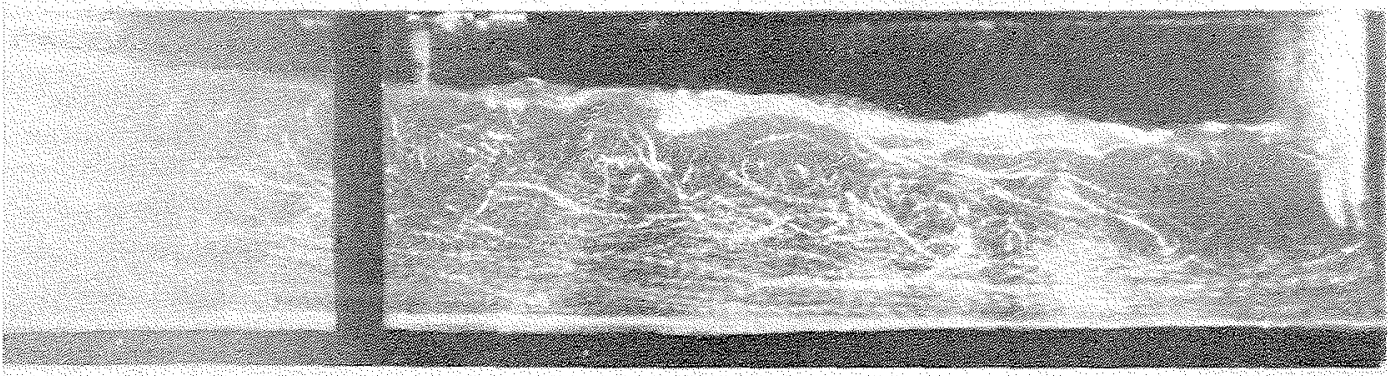

(b)
1/ 'Two forms of flow downstream of a submerged sluice gate. Depth upstream of sate $=7.5 \mathrm{in}$. Downstream depth $=5.4 \mathrm{in}$. Exposures : $0.2 \mathrm{sec}$

Denx formes de l'écoulement a l'aual d'une vanne noyće. Hateur d'eau à l'amont de la banne $=7,5$ ponces. Hanteur d'eau à l'aval $=5,4$ pou ces. Temps de pose: $0,2 \mathrm{~s}$. 
circulation, where normally there would be a continous return flow, Figure $1 b$. The photographs were taken with a "Zeiss Ikon" camera with the flow illuminated by a mercury-vapour discharge lamp flashing at 100 times a second [3]. The traces were droplets of a new white emulsion discovered by the author by mixing a mixture of olive oil and nitrobenzine prepared to the same density of water with a suitable percentage of water. Some idea of the scale of the photographs may be obtained by noticing the sluice opening which is $2 \mathrm{in}$. deep.

The situation exhibited in Figure 1 is very complex and we can only make the following guess about the physical sequence of events leading to it. Of the two eddies indicated in Figure $1 a$, the one nearer the gate appears to form first; it is probably caused by fluctuation either of the local turbulent stresses or of the pressure. Whatever the reason may be, once the eddy is initiated, momenta. rily a stream of fluid emerges from the jet into the circulation zone and proceeds towards $A$. This stream obstructs or retards the back flowing fluid and hence leads partly to an increase in the volume of fluid in region $B$, and partly to the downward deflection and so ultimately leads to the formation of the second eddy $B$ on the downstream side of $A$, thus creating two momentary circulation zones on top of the jet. The life either eddy is, however, short and is comparable with the time it took to develop, and both eddies eventually pass downstream and disappear, after which the normal form of flow with one circulation zone overlying the jet, (Fig. 1 b), prevails.

The above change in form of flow was also studied by photographing the motion of aluminium particles on the surface of water flowing through a sluice opening arranged in an Ahlborn tank [4] where a sharp-edged gate was arranged with one inch opening across two parallel walls placed

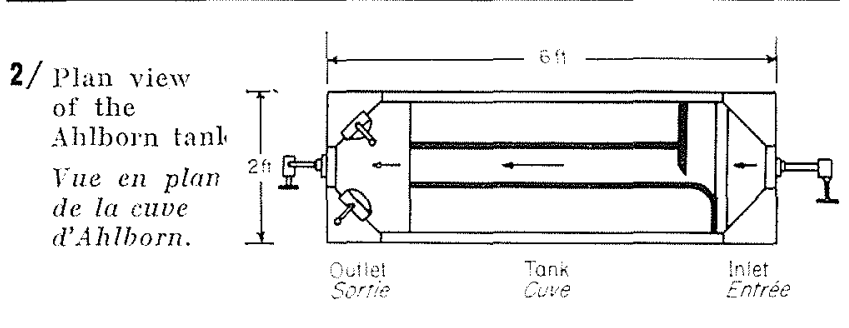

longitudinally in the tank in which water flowed from one end to another, Figure 2. The distance $s$ between the two walls was varied from 2 to 8 times the gate opening $d$. To avoid the formation of surface waves due to surface tension, the flow was adjusted to be less than 3 inches per second at the gate. 'The surface of water was illuminated by two $1000 \mathrm{~W}$ lamps, and photographs were taken by a camera mounted vertically over the working portion of the lank. Figure 3, showing two of the resulting photographs for $s=8 d$, clearly confirms the abnormal grouping of large eddies and the formation of two momentary circulation zones on top of the jet.

\section{References}

1) Nam (SK..A.). - Flow Patterns in a Sudmerged Liquid Jet Diffusing Under Gravity. Nature, vol. 210 (May 14 $1966), 694$

[2] Nan (S.K.A.). - Unsteadiness of the Circulation Pattern in a Confined Liquid Jet. Nature, vol. 212 November $12,1966), 753$.

(3) Nall (S.K.A.) _- Photographic Method for Measuring Velouty Profiles in a Liquid Jet.. The Engineer, vol. 221 (June 24, 1966), 961.

4] Wadis (R.P.). - A Photographic Study of Fluid Flow Between Banks of Tubes, Proc. Inst. Mech. E. vol. $142(1939), 379$

3/ Two patterns of flow shown by the motion of aluminium Jaken in an Ahlborn tank. Width of flow $=8 \mathrm{in}$. Ex posures : 1 sec.

Dena aspects de l'écoulement. Visualisation du mouvement it l'aide de flocons d'aluminium dans une cuve d'Ahlborn. Largent de l'écoulement $=8$ ponces. Temps de pose: $1 \mathrm{~s}$

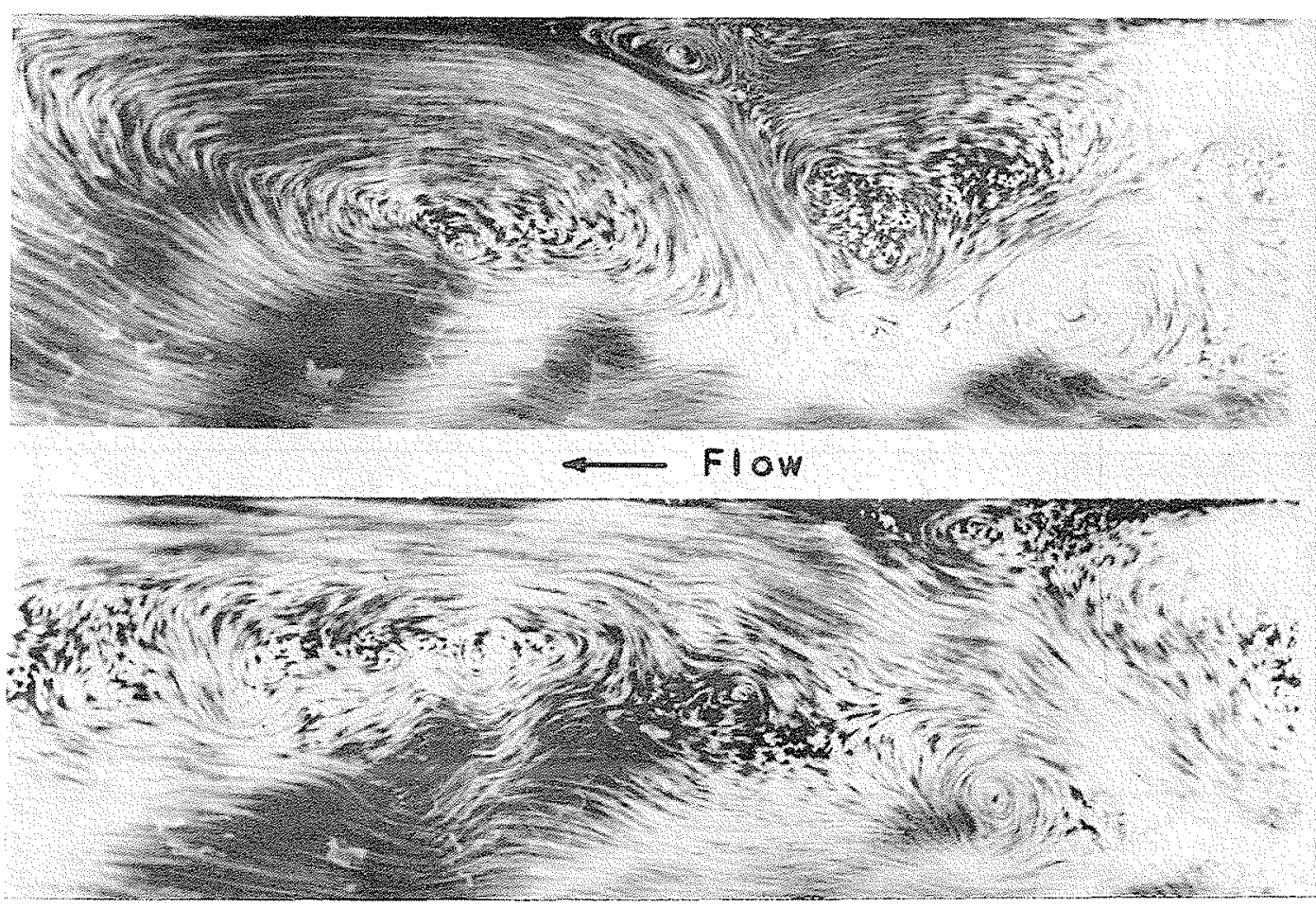




\section{ÉDITIONS DU CENTRE NATIONAL DE LA RECHERCHE SCIENTIFIQUE}

15, quai Anatole-France, PARIS-VII

C.C.P. PARIS 9061-11

Tél. : 705-93-39

\section{PUBLICATIONS \\ DE \\ L'ANNÉE GÉOPHYSIQUE}

Format in-4o coquille, broché

\section{OCÉANOGRAPHIE}

\section{Fascicule I}

par

GOUGENHEIM A., MARTIN J., LENOBLE J. et ROTSCHI H.

Introduction générale (1955-1959). Utilisation du courantomètre électrique à électrodes remorquées (1955-1956). Spectrophotomètre photoélectrique sous-marin (1957). Sur l'emploi du salinomètre australien du C.S.I.R.O. (1958), 78 pages.

\section{PRIX : $9,50 \mathrm{~F}$ \\ Fascicule II \\ par \\ DUBUCQ Cdt}

Hydrologie et dynamique des mers. Niveau moyen (Bibliographie), 56 pages.

PRIX : $6 \mathrm{~F}$ 